\title{
Multivariate analysis on the influence of physicochemical parameters on the calorific value of oils used in the petrochemical industry
}

\author{
Waldyr Fong-Silva ${ }^{\# 1}$, Luz Vargas-Ortiz ${ }^{* 2}$, Carlos Severiche-Sierra ${ }^{\# 3}$, Eduardo Espinosa-Fuentes ${ }^{\circledR 4}$, \\ Yesid Marrugo-Ligardo ${ }^{\# 5}$ \\ \# Universidad de Cartagena, Cartagena de indias, Bolivar, Colombia. \\ 1wfongs@unicartagena.edu.co \\ 33ceveriches@gmail.com \\ 5timiriguaco@hotmail.com \\ *Fundación Universitaria Tecnologico Comfenalco, Cartagena de indias, Bolivar, Colombia \\ ${ }^{2}$ lvargaso@tecnocomfenalco.edu.co \\ ${ }^{\circledR}$ Corporación Universidad de la Costa, Barranquilla, Atlántico, Colombia. \\ ${ }^{4}$ eduardo.espinosa.fuentes@gmail.com
}

\begin{abstract}
Multivariate statistical techniques were applied to identify the behavior of physicochemical parameters on calorific value in oil samples used in the industrial petrochemical sector of Mamonal in Cartagena de indias, Colombian Caribbean. Initially a physicochemical characterization of the samples was carried out through a principal components analysis, then a cluster analysis to identify similarities between the samples and to have a better description of the samples and finally a multiple regression model is fitted to determine the physicochemical factors that influence In the behavior of the calorific value of the oil samples. The results show that there are different associations between the physicochemical parameters; The cluster analysis yielded 4 groups of oil samples with different physicochemical behaviors and according to the criterion of loss of AIC information in the linear regression model, samples with low sulfur, sodium and ash content and high zinc content, Phosphorus and chlorine contribute to the increase of calorific value in the samples.
\end{abstract}

Keyword- Oil reused, Principal components analysis, Heat power, Physicochemical variables.

\section{INTRODUCTION}

The demand for treated oils to be used as an energy source would depend on the cost of the cleaned or cleaned oils, the cost of the fuels to be used if mixed and the behavior of the consumers of the new fuel [1,2,3]. The treatments applied to the used oils allow, through a degree of cleaning, to increase the percentage of the lubricant base present in the original oil, so that they are suitable for formulation and use [4,5]. That is, the raw material will be reused, thus achieving the minimum amount of waste discharged into the medium in liquid form $[6,7]$.

Interest in the combustion of waste oils has grown exponentially in recent decades as an important strategy to combat climate change through the production of renewable heat and electricity [8,9]. Because of its high heat capacity, the treated oil has great potential to be used as fuel not only for its properties and characteristics, but also for the need to have energy alternatives and safe energy supply, by releasing it from the components that make it a waste Dangerous $[9,10]$.

It can be used for combustion in furnaces, boilers, foundries, dryers, heating, plasticizer manufacturing processes and if it is released from all impurities in internal combustion engines; In this last aspect, this work is centered on the use of a calorimetric pump to determine the specific calorific value of a sample, carrying out its combustion in an oxygen atmosphere [11,12].

Multivariate analysis techniques are a very useful tool for differentiating groups within a given population based on different criteria [13]. For all of the above, it is established as the objective of this research To identify by means of a multiple regression statistical model the physicochemical parameters that influence the calorific value in samples of oil used in the industrial sector; For this a characterization of the samples with respect to said parameters is carried out and in this way to determine which have desirable conditions in terms of a calorific value meaning of use and application. 


\section{Population and sample}

\section{EXPERIMENTAL}

The population on which it was worked are used oils from the industrial sector of Mamonal in Cartagena de indias. The statistical sample corresponds to 118 samples selected from 9 types of oil used, as described in Table 1 below.

TABLE I. Description of the samples according to type and application

\begin{tabular}{|c|c|c|c|c|c|c|c|c|c|}
\hline Samples & 1 & 2 & 3 & 4 & 5 & 6 & 7 & 8 & 9 \\
\hline $\begin{array}{c}\text { Application } \\
\text { of the } \\
\text { machine }\end{array}$ & $\begin{array}{c}\text { Double } \\
\text { overhead } \\
\text { camshaft }\end{array}$ & $\begin{array}{c}\text { Reductor } \\
\text { motor }\end{array}$ & Motor & Motor & $\begin{array}{c}\text { Marine } \\
\text { Diesel } \\
\text { Engine }\end{array}$ & $\begin{array}{c}\text { Motor } \\
\text { Forklift }\end{array}$ & $\begin{array}{c}\text { Motor } \\
\text { Forklift }\end{array}$ & Motor & $\begin{array}{c}\text { Drive } \\
\text { motor }\end{array}$ \\
\hline Oil Mark & Mobil MX & $\begin{array}{c}\text { Shell } \\
\text { Omala } \\
220\end{array}$ & $\begin{array}{c}\text { Bracol } \\
\text { SAE50 } \\
\text { SE/CC }\end{array}$ & $\begin{array}{c}\text { Motor } \\
\text { Oil } \\
\text { SAE } \\
50\end{array}$ & $\begin{array}{c}\text { Fuel Oil } \\
\text { No.4 }\end{array}$ & $\begin{array}{c}\text { Shell } \\
\text { Rimula } \\
50\end{array}$ & $\begin{array}{c}\text { Shell } \\
\text { Rimula } \\
100\end{array}$ & $\begin{array}{c}\text { Havoline } \\
\text { SAE } \\
\text { 20W 50 }\end{array}$ & $\begin{array}{c}\text { Mix of } \\
\text { several }\end{array}$ \\
\hline
\end{tabular}

$60 \mathrm{~mL}$ aliquots were taken corresponding to the capacity of the sample receiving plastic containers.

\section{Laboratory Phase}

Measurements of the physical-chemical parameters: Moisture, Sulfur, Iron, Sodium, Zinc, Copper, Silicon, Phosphorus, Chlorine, Calcium, Sediments and Ash were carried out to the oil samples using the ICE 3000 series Atomic Absorption Spectrometers; As well as the calorific power thereof. The calorific value was measured with a calorimeter pump manufactured in the laboratory according to ASTM D240-02 and calibrated with Benzoic acid.

\section{Statistic analysis}

Statistical analysis of the information is carried out in the following order: Initially, the descriptive measures (mean, median, mode, maximum, minimum and coefficient of variation) of the physicochemical parameters in the oil samples are calculated and then obtained The main component analysis (PCA), which seeks to measure associations between quantitative variables, and similarities between individuals with respect to these variables. From the analysis of main components, a cluster analysis is performed to identify the oil samples that present similar behaviors with respect to the physicochemical parameters and finally a multiple regression model is performed to explain the behavior of the calorific value of the oils used In order to identify the parameters that influence the increase in the calorific value of the oil samples, the Akaike information criterion (AIC) was used for them, which yields the best regression model in terms of Loss of information.

\section{RESULTS AND DISCUSSION}

\section{Descriptive Analysis}

Table 2 contains the information of the descriptive statistics for the physicochemical parameters. The descriptive statistics show that the average calorific value of the oil samples is 11123.82, with little variability in the samples ( $\mathrm{CV}=9.51 \%)$, there is absence of some heavy metals in the oils; Such as copper, as well as sediments. It can be evidenced that there are samples with high content of iron, zinc and chlorine (maximum values of 1521.42, 1015.87 and 709.45 respectively).

TABLE II. Descriptive statistics of the physical-chemical parameters in used oil

\begin{tabular}{|c|c|c|c|c|}
\hline Parameter & Average & Minimum & Maximum & CV \\
\hline Humidity & 0,69 & 0,0091 & 2,44 & $119,06 \%$ \\
\hline Sulfur & 0,78 & 0,12 & 1,29 & $57,92 \%$ \\
\hline Iron & 243,9 & 2,44 & 1521,42 & $198,93 \%$ \\
\hline Sodium & 195,63 & 13,48 & 492,07 & $89,85 \%$ \\
\hline Zinc & 498,12 & 6,37 & 1015,87 & $90,56 \%$ \\
\hline Copper & 7,15 & 0,0041 & 17,4 & $85,66 \%$ \\
\hline Silicon & 12,92 & 0,28 & 49,69 & $126,81 \%$ \\
\hline Phosphorus & 12,35 & 1,06 & 24,89 & $77,48 \%$ \\
\hline Clorine & 292,97 & 15,8 & 709,45 & $90,18 \%$ \\
\hline Calcium & 288,01 & 20,08 & 1064 & $111,19 \%$ \\
\hline Sediment & 0,27 & 0,001 & 1,57 & $185,92 \%$ \\
\hline Ashes & 0,46 & 0,01 & 0,98 & $89,01 \%$ \\
\hline Calorific power & 11123,82222 & 8536,54 & 12102,44 & $9,51 \%$ \\
\hline
\end{tabular}


In general there is a lot of dispersion of the samples with respect to the different parameters, since there are coefficients of variation superior to $57 \%$, even reaching values above $100 \%$. The detected variations indicate that the samples present dispersed physicochemical behavior, so that there may be some with better conditions for effects of calorific power.

\section{Principal component analysis}

The correlation matrix between the physicochemical parameters for the oil samples is shown below. According to Table 3, important associations between the different parameters are observed. Wet oil samples have high sediment and ash content (correlations of 0.81 and 8.86 respectively). The sulfur content in the oil samples also shows an important and positive association with the zinc, copper, phosphorus, chlorine, calcium and ash content (correlations higher than 0.5).

Table III. Matrix of correlations between the Physical-Chemical parameters

\begin{tabular}{|c|c|c|c|c|c|c|c|c|c|c|c|c|}
\hline & Humidity & Sulfur & Iron & Sodium & Zinc & Copper & \begin{tabular}{|l|} 
Silicon \\
\end{tabular} & Phosphorus & Chlorine & Calcium & \begin{tabular}{|l} 
Sediment \\
\end{tabular} & Ashes \\
\hline Humidity & 1,00 & 0,48 & 0,15 & 0,12 & 0,69 & 0,52 & 0,29 & 0,10 & 0,12 & 0,11 & 0,81 & 0,86 \\
\hline Sulfur & 0,48 & 1,00 & 0,39 & 0,50 & 0,64 & 0,80 & 0,04 & 0,53 & 0,53 & 0,64 & 0,23 & 0,75 \\
\hline Iron & $-0,15$ & 0,39 & 1,00 & 0,04 & $\begin{array}{c}- \\
0,30 \\
\end{array}$ & 0,02 & 0,18 & 0,60 & 0,05 & 0,94 & 0,11 & $-0,16$ \\
\hline Sodium & 0,12 & 0,50 & 0,04 & 1,00 & 0,19 & 0,71 & 0,42 & 0,52 & 1,00 & 0,14 & $-0,31$ & 0,30 \\
\hline Zinc & 0,69 & 0,64 & 0,30 & 0,19 & 1,00 & 0,55 & $-0,26$ & $-0,20$ & 0,22 & $-0,01$ & 0,36 & 0,92 \\
\hline Copper & 0,52 & 0,80 & 0,02 & 0,71 & 0,55 & 1,00 & 0,22 & 0,63 & 0,72 & 0,27 & 0,11 & 0,71 \\
\hline Silicon & 0,29 & 0,04 & 0,18 & 0,42 & $\begin{array}{c}- \\
0,26\end{array}$ & 0,22 & 1,00 & 0,55 & 0,37 & 0,11 & 0,37 & $-0,01$ \\
\hline Phosphorus & 0,10 & 0,53 & 0,60 & 0,52 & $0, \overline{20}$ & 0,63 & 0,55 & 1,00 & 0,51 & 0,63 & 0,08 & 0,07 \\
\hline Chlorine & 0,12 & 0,53 & 0,05 & 1,00 & 0,22 & 0,72 & 0,37 & 0,51 & 1,00 & 0,16 & $-0,32$ & 0,32 \\
\hline Calcium & 0,11 & 0,64 & 0,94 & 0,14 & $\begin{array}{c}- \\
0,01\end{array}$ & 0,27 & 0,11 & 0,63 & 0,16 & 1,00 & 0,23 & 0,16 \\
\hline Sediment & 0,81 & 0,23 & 0,11 & $-0,31$ & 0,36 & 0,11 & 0,37 & 0,08 & $-0,32$ & 0,23 & 1,00 & 0,51 \\
\hline Ashes & 0,86 & 0,75 & $\begin{array}{c}- \\
0,16\end{array}$ & 0,30 & 0,92 & 0,71 & $-0,01$ & 0,07 & 0,32 & 0,16 & 0,51 & 1,00 \\
\hline
\end{tabular}

There is a positive association between the presence of copper and the sodium and zinc content ( 0.71 and 0.55), indicating that oil samples with a high copper content have high sodium and zinc contents. The phosphorus content also has strong positive linear associations with copper, silicon, chlorine and calcium contents (0.63, 0.55, 0.52 and 0.63 respectively). Oil samples with high ash presence are characterized by high zinc, copper and sediment content; While the density of the oils is directly related to the presence of zinc and sediments (correlations of 0.62 , respectively).

Table 4 shows that the first 4 factor axes accumulate $89 \%$ of the total variability of the information. Therefore, classification analysis is performed considering these axes in the analysis of principal components.

Table IV. Inertia and percentage radius of the eigenvalues

\begin{tabular}{|c|c|c|c|}
\hline Axis & Inertia & Accumulated Inertia & Proportion \\
\hline 1 & 5,002 & 5,002 & 0,42 \\
\hline 2 & 3,568 & 8,570 & 0,71 \\
\hline 3 & 2,132 & 10,702 & 0,89 \\
\hline 4 & 0,787 & 11,489 & 0,96 \\
\hline 5 & 0,390 & 11,879 & 0,99 \\
\hline 6 & 0,084 & 11,964 & 1,00 \\
\hline 7 & 0,034 & 11,998 & 1,00 \\
\hline 8 & 0,002 & 12,000 & 1,00 \\
\hline
\end{tabular}

Next, the resulting dendogram of Figure 1 is observed with the respective clusters. The dendogram shows 4 clusters, with respect to the behavior of the physicochemical parameters that were observed in them. The first cluster consists of samples 8, 3 and 4 (Oil samples applied to engines); The second for sample 1 (oil applied to 
double-shift dump trucks), the third for sample 9, 6 and 7 (oils used for the engine and forklift engine) and the last for samples 2 and 5 (oils used in engine Gearbox and Marine Diesel engine respectively).

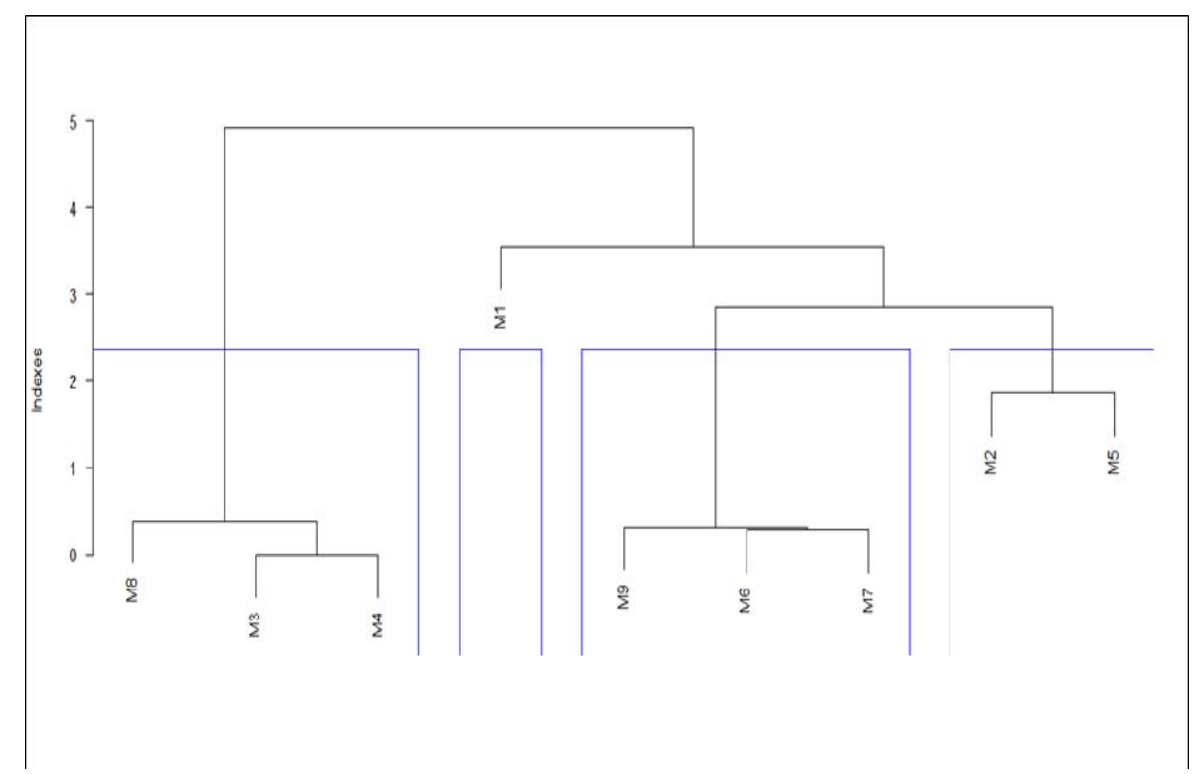

Fig 1: Dendogram of cluster analysis for oil samples

Next, in Figure 2, we have the first factorial plane associated to the analysis of principal components, in which we can observe the physicochemical characteristics of each of the samples.

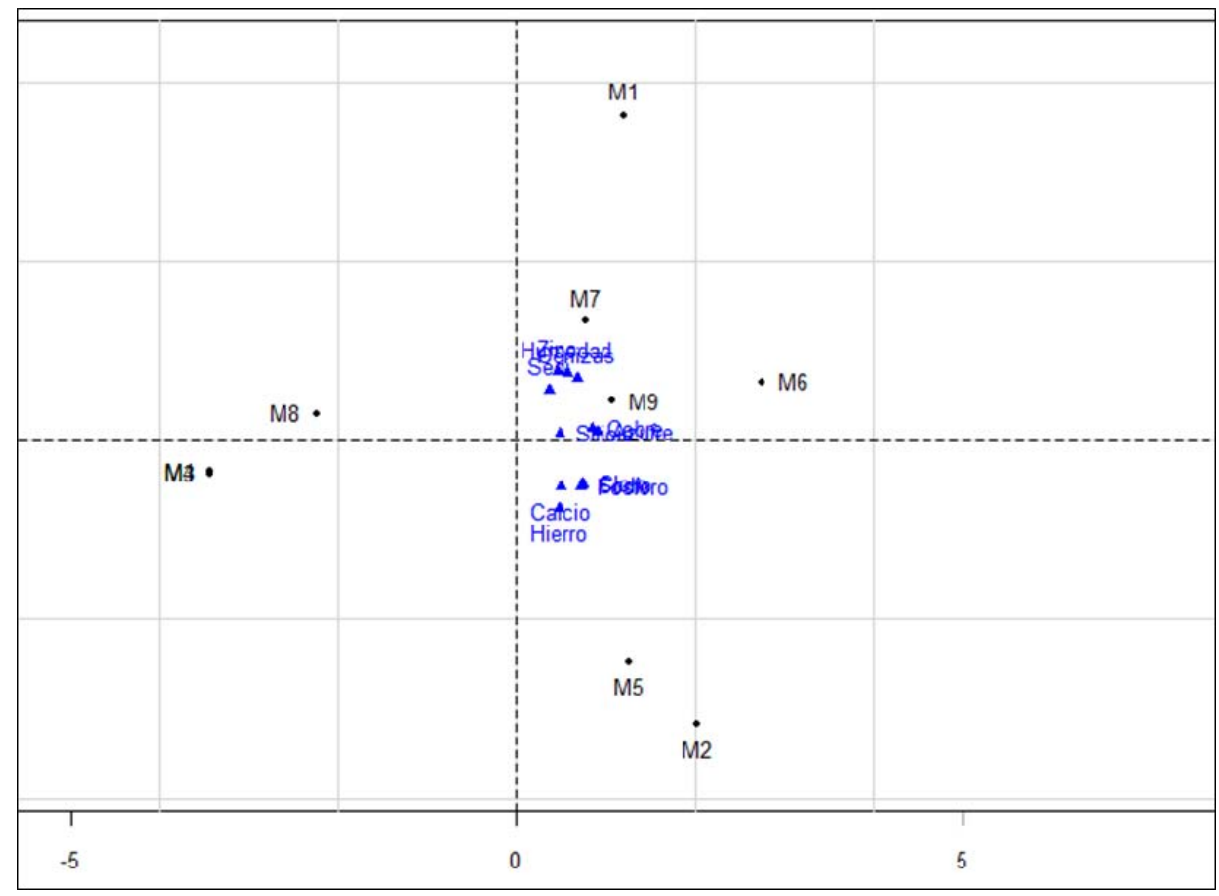

Fig 2: Factorial foreground for principal component analysis

According to the factorial plane and the direct data, the samples belonging to the first group present low levels of sulfur, iron, sodium, copper, silicon, phosphorus, calcium; As well as few ash and sediment residues. Group 2 is formed only by sample 1, this sample has low sodium level; While having high levels of silicon, sediment, ash and low humidity. Samples 9, 7 and 6 have high levels of sulfur, iron, sodium, zinc, copper, copper, phosphorus, chlorine, calcium and ash; As well as high humidity. The latter group consists of samples 2 and 5, which low levels of zinc and high levels of iron, sodium, silicon, phosphorus, chlorine and ash.

In Table 5 and according to the AIC criterion, the model that best explains the behavior of the calorific value according to the physicochemical parameters is the following one. 
Table V: Estimates of the coefficients of the multiple regression model for the calorific value

\begin{tabular}{|c|c|c|c|c|c|c|c|}
\hline Variable & Intercept & Sulfur & Sodium & Zinc & Phosphorus & Ash & Chlorine \\
\hline Estimate & 11642,42 & $-4700,23$ & $-54,616$ & 4,08 & 221,23 & $-1778,1477$ & 33,74 \\
\hline p-value & $0,0005^{* * *}$ & $0,0241^{* *}$ & $0,0814^{*}$ & $0,0468 * *$ & $0,0161^{* *}$ & 0,1629 & $0,0941^{*}$ \\
\hline
\end{tabular}

The coefficients of the parameters that were significant to model the behavior of the calorific value of the samples, in terms of the AIC criterion. The results indicate that oil samples with low content of sulfur, sodium, ash and high zinc content, phosphorus, chlorine; Have a higher calorific value. The R2 adjusted for this model is 0.9227 , indicating that $92.27 \%$ of the variability of calorific power is explained by the variables included in the model; While the p-value of the analysis of variance is 0.045 , showing that the model is significant; That is, the explanatory variables considered in the yes influence the calorific value. Accordingly, samples 3, 4 and 8 are the closest to this ideal behavior, which correspond to oils used in engines.

Then, in Table 6, the calorific value of the samples with the forecast according to the model is shown.

Table VI: Forecast for the calorific value of the different oil samples

\begin{tabular}{|c|c|c|}
\hline Sample & Calorific power & Forecast of calorific value \\
\hline M7 & 8536,54 & 8524,663387 \\
\hline M2 & 11515,5 & 10619,53341 \\
\hline M5 & 10741,63 & 10738,76641 \\
\hline M9 & 10865,97 & 11043,60152 \\
\hline M6 & 11417,8 & 11382,72742 \\
\hline M8 & 11490,5 & 11408,64228 \\
\hline M1 & 11741,82 & 11675,14079 \\
\hline M3 & 12102,44 & 11904,35188 \\
\hline M4 & 11702,2 & 11986,71605 \\
\hline
\end{tabular}

It is observed that group 1 (Samples 3, 4 and 8) are those that present the highest forecasts for calorific value and their real values are also within the highest. This indicates that the proposed model provides consistent and near-practical results.

\section{CONCLUSION}

According to the results obtained, the following conclusions are observed in the physicochemical behavior of used oils and their influence on calorific value in the Cartagena industry: 1) Descriptive statistics show a high variability of the samples with respect to the parameters Physicochemical; 2) The most important associations are observed between the content of ash and moisture, sulfur, zinc and copper; As well as between copper, sodium and sulfur and between calcium and iron, among others; 3) Cluster analysis yielded four groups of oil samples; 4) According to Akaike's criterion, the parameters influencing the calorific value are sulfur, sodium, ash, zinc, phosphorus and chlorine; Which explain 92.27\% of the calorific power behavior; 5) The samples of oil used in internal combustion engines, are those that present greater calorific power and those according to the adjusted model have the highest forecasts.

\section{REFERENCES}

[1] S. Anouti, G. Haarlemmer, M. Déniel, and A. Roubaud. "Analysis of Physicochemical Properties of Bio-Oil from Hydrothermal Liquefaction of Blackcurrant Pomace,” Energy Fuels., vol. 30, no.1, pp. 398-406, 2016.

[2] C. Severiche, R. Acevedo and J. Jaimes, "Landfill Mining As a Management Alternative for Solid Waste,” Producción Mas Limpia., vol. 9, no.1, pp. 115-123, 2014.

[3] C. Severiche and R. Acevedo " Biogas from Organic Waste and its Bet as Second Generation Fuels," Ingenium., vol. 14, no. 28, pp. 6 15, 2013.

[4] C. Ewulonu, and I. Igwe, "Properties of Oil Palm Empty Fruit Bunch Fibre Filled High Density Polyethylene, " International Journal of Engineering and Technology., vol.3, no. 6, pp. 458-471, 2011-2012.

[5] G. Mendes and P. Barbeira, "Detection and quantification of adulterants in gasoline using distillation curves and multivariate methods," Fuel., vol. 112, pp. 163-171, 2013.

[6] K. Sarker, "Review and Comparison of Various Properties of Jatropha oil Biodiesel," International Journal of Engineering and Technology., vol. 7, no .6, pp.1965-1971, 2015-2016.

[7] Theja and Y. Rao, "Investigations on Effect of Fuel Injection Pressure on Performance and Emissions of Linseed Blends in a Diesel Engine," International Journal of Engineering and Technology., vol. 8, no. 2, pp. 1053-1062, 2016. 
[8] Yusri1, S. Osman, R. Mamat, O. Awad and S. Rosdi. "Experimental investigation of butanol gasoline blends effect on the mass fraction burned in a spark ignition engine," International Journal of Engineering and Technology., vol. 8, no.6, pp. 2571-2577, 20162017.

[9] M. Abdullah, A. Saat and Z. Hamzah, “Assessment of the impact of petroleum and petrochemical industries to the surrounding areas in Malaysia using mosses as bioindicator supported by multivariate analysis," Environ Monit Assess., vol. 184, no. 6, pp.3959-69, 2012.

[10] F. Yunxia, C. Xiaoli, X. Yupeng and T. Songbai, "Corresponding Factors Influencing Crude Oils Assay Using Low-field Nuclear Magnetic Resonance," China Petroleum Processing and Petrochemical Technology., vol. 16, no. 2, pp. 34-39. 2014.

[11] M. Kumar, G. Nataraj, S. Selvan, "A comprehensive assessment on the effect of high octane fuels induction on engine’s combustion behaviour of a Mahua oil based dual fuel engine," Fuel., voL. 199, pp. 176-184, 2017.

[12] X. Wen, S. Jian and J. Wang, "Prediction models of calorific value of coal based on wavelet neural networks," Fuel., vol. 199, pp. 512-522, 2017.

[13] J. Villazon, G. Martin, and Y. Cobo, “Análisis multivariado de las propiedades químicas de los suelos pardos erosionados," Ctro. Agr., Santa Clara., vol. 44, no. 1, pp. 56-62, 2017.

\section{AUTHOR PROFILE}

Waldyr Fong-Silva. Mechanical Engineer at Bolivar University, University Teaching Specialist at Magdalena University, Master's Degree in Education at the University of Seville, Master's Degree in Physical Sciences at the University of Cartagena and Doctorate in Sciences at the Dr. Rafael Belloso Chacin University. He is currently Director of the Metrology Program of the University of Cartagena.

Luz Vargas-Ortiz. Received the title of Statistic in 2006 by the University of Cordoba, the degree of Magister in Statistic by the National University of Colombia (2014). She is currently a Research Professor at the Comfenalco Technological University Foundation. Expert in multivariate analysis statistics and time series.

Carlos Severiche-Sierra. He received the title of Chemist in 2008 from the University of Cartagena, a title in 2011 of Specialist in Sanitary and Environmental Engineering by the University of Cartagena, the degree of Magister in Sustainable Development and Environment by the University of Manizales (2013), degree Specialist in Health and Safety at Work (2017) from the Autonomous University of the Caribbean, he is currently a Doctor of Science candidate at the Dr. Rafael Belloso Chacin University. He is currently a Research Professor at the University of Cartagena and Comfenalco Technological University Foundation.

Eduardo Espinosa-Fuentes. He received his degree in Chemistry in 2004 from the University of Cartagena, a Master's degree in Chemistry from the University of Puerto Rico (2010) and a Doctor of Chemistry from the University of Puerto Rico (2014). He is currently a research professor at the Corporación Universidad de la Costa.

Yesid Marrugo-Ligardo. Bachelor in Biology and Chemistry, Food Engineer, Food Science and Technology Specialist, Master in Food Science and Technology, he is currently a Doctor of Science candidate at the Dr. Rafael Belloso Chacin University. He is currently a Research Professor at the University of Cartagena. 